\title{
Auction design and auction outcomes
}

\author{
Pantelis Koutroumpis ${ }^{1}$ - Martin Cave ${ }^{2}$
}

\begin{abstract}
We study the impact of spectrum auction design on the prices paid by telecommunications operators for two decades across 85 countries. Our empirical strategy combines information about competition in the local market, the level of adoption and a wide range of socio-economic indicators and process specific variables. Using a micro dataset of almost every mobile spectrum auction performed so far-both regional and national—we show that auction design affects final prices paid. Two designs (SMRA with augmented switching and CCA with core pricing) result in auctions with systematically higher normalized returns. Further, we document that spectrum ownership appears to affect prices paid in subsequent auctions. We discuss the mechanisms of cost minimization and foreclosure faced by operators in different regulatory environments. Our findings have implications for policy-makers and regulators.
\end{abstract}

Keywords Auction · Digital communications $\cdot$ Spectrum $\cdot$ Market power

JEL Classification D44 · C78 · L96

The authors are grateful to Dot Econ for the provision of data but are solely responsible for the analysis herein.

$凶$ Pantelis Koutroumpis

pantelis.koutroumpis@oxfordmartin.ox.ac.uk

1 Oxford Martin School, Oxford University, Oxford, UK

2 Department of Law, London School of Economics, London, UK 


\section{Introduction}

Auctions are mechanisms that help allocate resources to those that can use them most valuably. Numerous economic transactions are conducted through auctions including treasury bills, foreign exchange, assets under privatization, mineral and spectrum rights among others (Klemperer 1999; Binmore and Klemperer 2002, Salant 2014). The local market conditions, the types of goods auctioned and the priorities faced by the government help shape the overall allocation mechanism and the specific rules of the process. For example spectrum rights represent contracts on rivalrous and scarce natural resources where operators are granted exclusive rights in a band of airwaves ${ }^{1}$ for a specified period of time. In cases where scarce goods under public control are auctioned, regulators and antitrust agencies try to prevent collusive, predatory and entry-deterring behaviors while maximizing the social gains.

Auction design, rules and regulatory requirements have been central to the political debate for decades. The rapid adoption of mobile communications and digital technologies has rendered a previously underutilized natural resource-the electromagnetic spectrum - a commodity of major importance. To this end a range of spectrum allocation processes have been used by policy makers in an attempt to maximize the economic and social returns to the local and national economies. The literature suggests that various allocation methods ranging from administrative awards and beauty contests to alternative auction designs, lead to different levels of normalized social returns for the resource in question (Cramton 2013). ${ }^{2}$

Despite the progress in developing auction mechanisms, auction design "is not "one size fits all' and must be sensitive to the details of the context" (Klemperer 2002a). The context represents the specific market structure and prospects, the regulatory constraints and the overall economic environment in which firms operate. Auction outcomes are affected by less obvious parameters, for example a bidder may feel the thrill of a win over and above her value of receiving the object (Roider and Schmitz 2012). The disclosure of feedback is another novel instrument in design mechanisms resulting in higher revenues (Jehiel 2011). Reserve price levels, the use of absolute auctions (without a minimum price) bid floor or ceiling levels, public or secret reserve prices or even the threat of cancellation have been found to affect outcomes too (Gavious et al. 2002; Che and Gale 1998; Chen and Chiu 2011; Engers and McManus 2007; Rosenkranz and Schmitz 2007).

In the recent history of spectrum auctions researchers observed various types of imperfect outcomes both because of the methods used (the actual design of the process) as well as the understanding of the context. Common methodological oversights include the oversupply of licenses compared to the local market needs (Swiss and Italian $3 \mathrm{G}$ auctions, 2000), ${ }^{3}$ the lack of adequate provisions to prevent strategic bidding or collusion among operators (tacit or otherwise, including cases of bid signaling in FCC auctions; Cramton and Schwartz 2002; Bajari and Yeo 2009) and high reserve

\footnotetext{
1 In a given region or country.

2 http://econ.ohio-state.edu/seminar/papers/120831_TBA.pdf.

3 This can be attributed to one operator pulling out before the auction or not participating at all.
} 
prices for single or packaged lots that end up unsold (Indian auction 2016, for 700, $900 \mathrm{MHz}$ and $2.4 \mathrm{GHz}) .{ }^{4}$ An auction may result in suboptimal social returns in other cases, for example when investments are delayed or cancelled due to high-instead of low-prices paid. Typical examples are the $\mathrm{UK}^{5}$ and German $3 \mathrm{G}$ auctions in the early 2000s where operators paid orders of magnitude more than other operators in similar socioeconomic contexts (Klemperer 2002b). Some argue that elevated costs of entry in mobile services may have an impact on investment for coverage and quality of connections, and lead to higher prices and subsequently lower adoption rates. As we show in Sect. 4 this assertion has often been disputed.

The simple question "are auctions socially optimal allocation processes compared to other mechanisms like structured negotiations or beauty contests?" may be hard to answer if other parameters are not taken into account. For example, a competitive mechanism can not directly induce a specific type of behavior to participants but may only provide a framework within which they will be expected to navigate. This oversight is also found in the literature of government security sales where the key aspects that affect an auction's results are market thickness - the guarantee that there is a large pool of bidders for the auctioned lots - and low entry costs (Klemperer 2002a). Across a range of experiments with different auction designs there are largely inconclusive results ${ }^{6}$ regarding external to the design parameters, particularly with the issue of market power as an impediment to efficient outcomes. Other exogenous parameters like the structural imperfections related to market power (like a dominant position or the participation of a new entrant) may also affect the final outcomes (Morey 2001).

In this paper we look into the impact of auction design on final prices paid-controlling for many aspects of the context and structure we described. Our focus is the mobile communications market where spectrum auctions have gradually displaced beauty contests as the primary mechanism for assigning high value spectrum. Such auctions combine complexity with far-reaching economic impacts, and have stimulated many of the theoretical developments in the past decade. As a result of this activity we now have records of hundreds of spectrum auctions throughout the world. This makes it possible to address empirical questions about spectrum auction design and auction outcomes. This is a first attempt—-to our knowledge —of this kind. We address two key questions: First whether auction design influences the outcome in terms of revenue derived, measured by a standard nominal metric of $\$$ per $\mathrm{MHz}$ per unit of population (in the coverage area). And second whether the amount paid for spectrum by an operator is linked to that operator's legacy spectrum holdings.

To address these questions we use a micro-dataset of more than 10,000 lots covering 85 countries and 371 auctions for the period 1994-2015. We find that any auction design is preferable to administrative awards, first come/first serve awards and beauty contests in terms of the normalized returns. This possibility suggests that auctions are better suited to infer true valuations for scarce resources compared to less rigid or

\footnotetext{
4 This ended with only $10 \%$ of the envisaged revenues due to very high reserve prices by the regulator.

5 http://news.bbc.co.uk/2/hi/business/727831.stm.

${ }^{6}$ See Simon (1994); Malvey et al. (1996); Nyborg and Sundaresan (1996); Reinhart and Belzer (1996); Ausubel and Cramton (1998).
} 
transparent processes. Apart from the overall format some specific components of the design have a significant impact on the final price paid. These include the pricing rules (core pricing, "pay as bid", "highest loser", etc.), the flexibility to choose among combinations of lots (packaged bids) and the switching of spectrum blocks before the final allocation. The leading combinations in terms of the normalized returns are SMRA auctions with augmented switching and the CCA with core pricing. There is substantial heterogeneity across regional and national licenses while local socioeconomic conditions help explain a substantial proportion of the residual effects.

We further look into the market power across regions and its link to the final prices paid. We reconstruct the panel to account for all mergers and acquisitions in the telecommunications industry over the past decades and test the importance of an operator's customer base, its status as incumbent or entrant and the local regulations concerning dominant firms. Our results show that structural imperfections in local markets combined with local regulations have a major impact on normalized returns.

The paper is organized as follows. Section 2 describes our data sources and econometric approach. Section 3 describes the types of spectrum auction, Sect. 4 gives our answer to the first question above, together with a brief attempt to set it in the broader context of spectrum management. Section 5 addresses the second question in a similar framework. Section 6 summarizes and concludes.

\section{Types of spectrum auctions}

In this section we describe the key auction designs that have been used for spectrum and the rationale behind each of their designs. Often the experience from previous auctions lead regulators and governments to try various rules and provisions that help prevent collusion among participants, motivate truthful bidding, guarantee service provision after the end of the process and eventually increase social-rather than private-returns. This subtle trade-off between auction participants whose bidding strategies often aim to maximize profits, strengthen their position in the regulated market and effectively face lower competitive pressure needs to be balanced with the maximization of social returns that government and regulators-in most cases-seek to achieve. Some simple designs without specific provisions for these conflicting interests have been exploited in the past in various occasions (Klemperer and Pagnozzi 2002).

Before we introduce the various designs we try to sketch the overall process from the announcement of the auction until the grant of the licenses. A regulator (and less often a ministry or government) announces the auction of one or more spectrum lots in certain frequency bands $(1800,2600 \mathrm{MHz}$, etc.). Each of the lots has a fixed bandwidth $(5,10 \mathrm{MHz}$, etc.) that can be paired $(2 \times 5 \mathrm{MHz})$ or unpaired (single $5 \mathrm{MHz}$ lot) with another part in the same frequency band. For example, in 2014 Ofcom (the UK regulator) auctioned 4 lots of $2 \times 5 \mathrm{MHz}$ (paired) in the $800 \mathrm{MHz}$ band, 1 lot of $2 \times 10 \mathrm{MHz}$ in the same band (with universal service obligations) along with 9 lots of $5 \mathrm{MHz}$ (unpaired) in the $2600 \mathrm{MHz}$ band and 14 lots of $2 \times 5 \mathrm{MHz}$ (paired) in the same band (Ofcom, 2014). The firms wishing to enter the auction had to qualify for participation and register. Conditional on previous ownership they may bid for some or all of the lots. Regulators in order to achieve a level playing field often set 
aside some lots for entrants or firms that have limited (or no) spectrum holdings to compete with other players. Thus the envisaged "balance" in the competitive landscape is prioritised at the expense of a process that could yield additional public revenues but would likely decrease competition in the market and possibly the social returns of mobile communications.

Before getting to the discussion of the various designs it is important to note that not all bands have the same value for commercial and other frequencies. In the commercial mobile communications $(2 \mathrm{G}, 3 \mathrm{G}, 4 \mathrm{G})$ lower frequency bands are more valuable for operators as these can better penetrate building walls compared to higher frequencies. The higher frequencies $(2600 \mathrm{MHz})$ can not reach the building interiors so well but can instead offer more capacity which is essential for higher throughput rates. The $1800 \mathrm{MHz}$ band (or $1900 \mathrm{MHz}$ in some areas) offers a compromise between these two cases but the overall mix of existing spectrum ownership, the density of cell towers, the local geography and the selection of lots auctioned allow operators to shape their bidding strategies and assess their relative importance for service delivery. For clarity, in our analysis the commercial lots include the following frequencies: 800, 900, 1800, 1900, 2100 and $2600 \mathrm{MHz}$.

\subsection{Simultaneous multiple round auction (SMRA)}

The most typical auction design (used in various settings like in fine art and treasury bills) is the ascending auction where all participants bid for the same object until the highest bidder wins (often named as English auction). The auction continues until there is no more bidding for an object. The SMRA is an ascending auction for multiple lots that are included in the process and runs simultaneously for all of them. In this case after the end of each round the participants re-evaluate their strategies conditional on the bidding of other participants. When there is no additional demand for any of the lots the allocation process begins. In some cases the bidding process does not involve specific lots but generic ones. Operators interested in the $2600 \mathrm{MHz}$ band for a lot would not bid for a specific lot (whose frequency ranged would be fixed) but a generic lot in that entire auctioned band. During the allocation process these generic lots are distributed (according to preferences or further bidding) to the interested parties.

While this design is relatively straightforward for participants it has been observed that bidders may face a "lot aggregation" risk while trying to safeguard their preferred parts. For this purpose, some additional rules have been used including the ability to switch lots with other bidders (switching rule). Staged bidding for the allocation of generic lots can also partly alleviate the aggregation risk. Other rules like caps in the maximum number of lots acquired (or frequency) and set-asides have also been used with the aim to improve the competitive landscape.

\subsection{Sealed bid auction}

This is a single round auction where participants submit their bids in a sealed envelope (or another secretive manner). Since there is no further bidding lot winners are 
determined after the bid submission. There are two ways to determine prices paid: with first price or pay as bid auctions where participants pay for the amount they actually bid; or with second price bid comparison where they pay the second highest bidders price (this can be the lowest winner's bid or highest loser's). More recently this process has been changed to include generic lot bidding and combinatorial or packaged bidding allowing participants to bid for combinations of existing lots rather than single lots. In sealed bid auctions the simplicity of a single round comes at the expense of price discovery from participants. Given that there is only one round available, participants can not elicit other parties' interests hence reducing their price discovery capacity. However, in some cases this process allows wider participation as it increases uncertainty for incumbents and creates opportunity for entry. The introduction of packaged bids (combinatorial sealed bid auctions) and multiple attributes for bids (coverage obligations along with price) has led to bids ranked by score instead of price alone.

\subsection{Combinatorial clock auction}

More recently the various limitations associated with the SMRA design (for example in the early 2000s for the $3 \mathrm{G} \mathrm{UK}$ and German auctions) and other simpler clock auctions has led several regulators to adopt a different multi round format. This design is often implemented with generic lots allowing for combinations of lots too. The bidding process starts with an ascending clock for each category. This initial ascending clock phase, during which bidders state their demands in response to the current prices is followed by sealed bid second price rule for package bids. In the allocation phase the regulator computes the highest value allocation and the corresponding payments. In this stage (Ausubel et al. 2006) the final prices are adjusted so that they are within the "core" pricing area. These are referred to as Core Pricing designs for combinatorial clock auctions. ${ }^{7}$ This design eliminates aggregation risks posed by SMRA and drives participants to engage in truthful bidding strategies. At the same time, it can cope with combinations of lots across bands and allows for specific spectrum floors and other auction specific rules. On the downside CCA is more complex that the other key designs and the final prices paid may differ from actual bids (Levin and Skrzypacz 2016).

Other types of auction designs include the English auction (open outcry ascending bid auction), the Dutch auction (descending auction until someone accepts the current price or the reserve price is reached), the Beauty Contests with or without a financial bid criterion (a mechanism without specific allocation rule, i.e., highest price bidder wins, but a combination of parameters that may include the speed of delivery, the reputation of the bidder, etc.), Standard Clock auctions (without package bids or core pricing) and First Come First Served auctions (where all incoming bids are considered and the lots can be sold at any given time with or without specific criteria). Other designs include the Anglo Dutch auctions where a first round of ascending bidding is followed

\footnotetext{
7 CCA designs can have several variations in terms of the first stage combinations and second stage allocations. For example, allocation can come with second prices or core pricing rules.
} 
by a second round of descending prices. In this case the highest bidder gets a cash premium irrespective of the outcome of the second round (van Bochove et al. 2012).

Other parameters that often affect bidding strategies and form allocation are the levels of reserve prices for each lot-and the willingness to safeguard that these will be kept in any possible outcome (i.e., in case no participant meets them, see for example the auction in Medudula et al. 2016).

\section{Data and econometric approach}

The dataset used in this study is a thorough collection of spectrum auctions in the past two decades. It includes 85 countries over 1994-2015 and 13,059 lots from 41 frequency bands. The data come from the DotEcon database ${ }^{8}$ and manual collection by the authors. A full description of the variables can be found in Table 5 of the "Appendix" and an indicative breakdown of normalized prices per country and year in Fig. 5. For a full list of the frequency bands included in our sample see Table 6.

In this paper we deal with all types of auctions that have been used in the past 20 years for spectrum allocation around the world. This includes the categories mentioned in Sect. 2 and the specific rules that accompanied them. We particularly control for the existence of package bids or switching of lots along with pricing rules (first, second, second-highest loser and second-lowest winner). Further to the auction design our data includes information about the number of rounds that each auction took to complete, the days that this process lasted, the population coverage objectives for each lot, the local population density, ${ }^{9}$ the level of mobile adoption in each area, the duration of each license, the size in $\mathrm{MHz}$ of each lot, whether the lot was paired or not, the number of bidders for each lot, the number of licenses for each frequency, the income levels in each area and whether these lots were allocated for national or regional coverage. Moreover, we add country controls and year effects to account for various country and year specific shocks that may confound the underlying process. Last we also control for the impact of different frequency bands in the price paid for each lot with a full set of frequency band controls.

Having described our control variables, we discuss the limitations of our data. In particular, we have no information about the existence of set-asides or caps that may have been imposed in various settings. To alleviate this omission, we use information about the number of bidders for each lot and whether an entrant takes part in this bidding. From this we flag as possible set-asides the lots that have only (one or more) entrant bidders. This may not be fully consistent as some lots may attract entrants only but it is the closest we can get to infer this information with the given data. We also run regressions at the auction level (instead of the lot level) to make sure that each auction design is given its merit without an observation bias that favours regional auctions with multiple lots.

To compare different auction outcomes, we use a normalized metric of the final prices paid. This is computed as the natural logarithm of the price of a lot divided by

\footnotetext{
8 A leading consultancy firm.

9 This is at the country level only.
} 


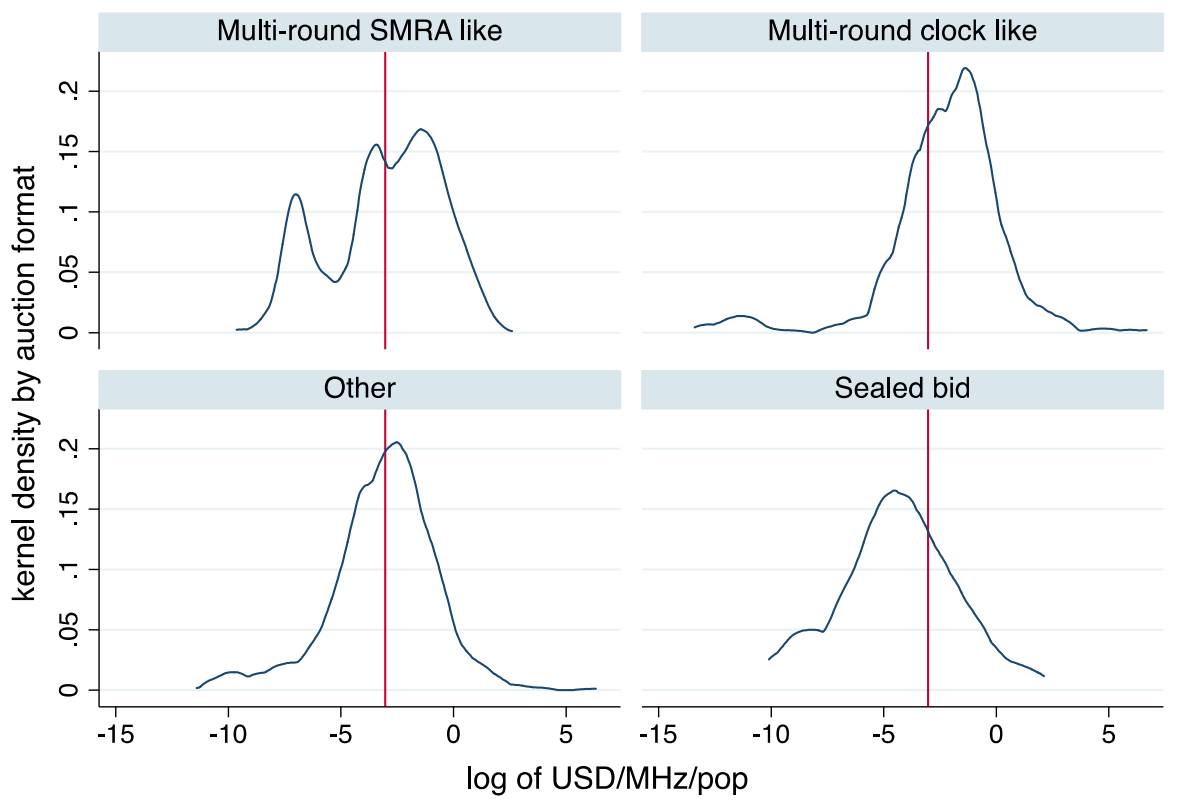

Fig. 1 Normalized returns (\$/MHz/pop) and generic auction format

size of the spectrum (in $\mathrm{MHz}$ ) and the population covered (\$/MHz/pop). To avoid a bias toward auctions with more lots included than others, like the US regional auctions, we average the normalized price paid for lots of the same frequency and region (for regional only auctions). Therefore the analysis - in most parts-is not based at the lot level but at the frequency band level by auction and region. ${ }^{10}$

In our analysis we compare different auction designs, pricing and other rules based on this normalized metric. Figure 1 compares the generic auction formats and shows that SMRA-like and multi-round clock-like auctions designs often return higher normalized revenues. We further show (Fig. 3) that packaged bids have higher chances of increasing the final prices paid (normalized) and also that not allowing block switching will lead to similar outcomes (Fig. 4).

Our empirical specification models the normalized (log) of average prices price ${ }^{11}$ of a lot $k$ for each auction, frequency band and sub-national region (i.e., the price per $\mathrm{MHz}$ and population covered) sold at a country $i$ at time $t$ as a function of the auction

\footnotetext{
10 Results at the lot level have been computed and are available upon request.

11 In our analysis we do not use reserve prices as a dependent variable. The reason is that we are primarily interested in the final prices paid for allocated spectrum and (high) reserve prices often lead to an auction cancelation, lots being unsold and lower revenues. If these are below the true valuation of bidders or the prices they are willing to pay through other motives (collusion, foreclosure), reserve prices should not drive outcomes over and above our set of existing controls.
} 
specific parameters as well as a range of local competition and regional socio-economic conditions. Our baseline empirical specification is:

$$
\log \left(P_{i k t}\right)=\sum_{j=1}^{4} D_{i k t}^{j}+X_{i k t}+\varphi_{i}+\psi_{t}+\epsilon_{i k t},
$$

where $D_{i k t}^{j}$ is the auction format [SMRA-like, Clock-like, Sealed bid, other], pricing rule, and auction description. $X_{i t}$ is a vector of lot and locational and economic characteristics. $\varphi_{i}$ is a dummy variable to control for unobserved time-invariant country effects and $\psi_{t}$ is a dummy variable for unobserved year effects. In order to increase the granularity of the auction designs we further look into eight award class descriptions ${ }^{12}$ :

$$
\log \left(P_{i k t}\right)=\sum_{m=1}^{12} D_{i k t}^{m}+X_{i k t}+\varphi_{i}+\psi_{t}+\epsilon_{i k t}
$$

The static nature of models (1) and (2) may overshadow other structural effects that play a critical role in lot allocation and pricing. For example, the ownership of previous spectrum holdings may have a significant effect on this relationship. Similarly, the range of spectrum holdings (in various frequency bands) and the level of these investments (in $\mathrm{MHz}$ ) may also be crucial for our analysis. For this, we also embark on a dynamic analysis to assess how previous ownership and operator status (incumbent/entrant) influence the final prices paid that we observe. For this purpose, we look at each country's auctions and add the frequencies held by each operator. This is a complex process as operators often merge or acquire others, buy and sell spectrum between auctions or even change their names across different award processes. ${ }^{13}$ This analysis uses the lot level prices paid as the average prices would not allow us to control for the operator level effects (entry and previous ownership) explicitly.

In this process we introduce three new metrics: Entrant ${ }_{i j t}$ is a binary variable for operators (denoted by $j$, in country $i$ at time $t$ ) that have no ownership of spectrum, $S_{i j t}$ is the \% ownership of any spectrum in the previous period and $S_{i j t}^{t o t}$ the average $\%$ spectrum ownership in all previous periods. We also add a control variable for sub $1 \mathrm{GHz}$ frequencies $L_{k}$. This is based on all (measured in $\mathrm{MHz}$ ) spectrum held from any previous auction and the fraction each operator won. $S_{i j t}$ and $S_{i j t}^{t o t}$ take values from 0 to 1 . With these changes Eq. (2) now becomes:

$$
\log \left(P_{i j k t}\right)=\text { Entrant }_{i j t}+L_{k}+\sum_{m=1}^{12} D_{i k t}^{m}+X_{i k t}+\varphi_{i}+\psi_{t}+\epsilon_{i k t},
$$

\footnotetext{
12 Award class descriptions include: First come first serve, Beauty contest, Beauty contest with financial bid criterion, Auction-unknown, Auction-other, One-shop sealed bid auction, Standard clock auction, Standard SMRA auction, Standard SMRA auction with augmented switching, Standard CCA with core pricing and Unknown.

13 Operators can change names, merge (within countries) or become part of another group. Therefore there is a temporal evolution of operators and groups, i.e., Panafon Greece becomes Vodafone in 2001 (part of Vodafone group). This means that Panafon as an operator remains the same (same id) but group changes from sole company (Panafon_id) to group (Vodafone group).
} 
Introducing the memory component it becomes:

$$
\log \left(P_{i j k t}\right)=S_{i j t}+L_{k}+\sum_{m=1}^{12} D_{i k t}^{m}+X_{i k t}+\varphi_{i}+\psi_{t}+\epsilon_{i k t},
$$

And with full memory it becomes:

$$
\log \left(P_{i j k t}\right)=S_{i j t}^{t o t}+L_{k}+\sum_{m=1}^{12} D_{i k t}^{m}+X_{i k t}+\varphi_{i}+\psi_{t}+\epsilon_{i k t}
$$

To capture the actual dynamics of the \% ownership we add the first and second order polynomial terms of the full memory, so that it becomes ${ }^{14}$ :

$$
\log \left(P_{i j k t}\right)=\sum_{f=1}^{2}\left(S_{i j t}^{t o t}\right)^{f}+L_{k}+\sum_{m=1}^{12} D_{i k t}^{m}+X_{i k t}+\varphi_{i}+\psi_{t}+\epsilon_{i k t},
$$

Bands for popular technologies $(2 \mathrm{G}, 3 \mathrm{G}, 4 \mathrm{G})$ are often more expensive compared to other spectrum parts. For this on top of the frequency band controls already included we present the findings of this analysis for each cluster separately (for 2G, 3G and 4G and then for all other frequencies).

\section{Auction design and spectrum auction revenues}

One of the long-lasting controversial issues in spectrum management is whether high prices in spectrum auctions have adverse repercussions in communications markets. To put it in a more challenging way, 'Are spectrum auctions ruining our grandchildren's future?' (Cave and Valletti 2000). A major matter of dispute is the extent to which spectrum prices are a sunk cost, so that while expectations of revenues and costs influence bidding in an auction, prices actually paid in that auction have no impact on the subsequent pricing of the spectrum-using service.

The industry association (GSMA) supports that high spectrum prices have a negative impact on consumers as the added costs are passed through higher prices. For this GSMA argues that government efforts to maximise revenues from spectrum auctions can damage the wider economy (GSMA 2017, p. 3). On the other hand, Cambini and Garelli (2017, p. 2) conclude on the basis of an empirical investigation using a dataset of firms in 24 countries over 10 years that (spectrum) availability and fees seem uncorrelated with mobile operators' revenues, This suggests that spectrum prices do not significantly affect industry performance supporting the 'sunk costs' hypothesis.

The first empirical question to be investigated is whether different auction designs do or do not generate systematically different prices. On the combined assumption of sunk costs and bidder rationality (no winner's curse), there would appear to be no necessary problem with using a design, which raised more cash for the government. For those taking the opposite view, higher prices would entail adverse consequences.

\footnotetext{
14 We tested with polynomials of 4 th order finding similar estimates. Since the simpler specification resulted in similar accuracy we followed the 2 nd order approach.
} 
The median price in the regional lots is $0.124 \$ / \mathrm{MHz} /$ person and for the national lots $0.151 \$ / \mathrm{MHz} /$ person. Using these we anchor our analysis and interpret the estimated coefficients as deviations from these median prices. In the case of regional and national lots (Table 1) we find that the "Pay as Bid" pricing rule has a strongly positive and significant effect on the normalized returns of a national auction resulting in 0.059 $\$ / \mathrm{MHz} /$ pop compared to other pricing rules as expected. In regional auctions the second price-highest loser pricing yields 0.086 \$/MHz/pop when used. Looking into auction formats (columns 3 and 4) we find that SMRA designs return 0.044 $\$ / \mathrm{MHz} /$ pop and $0.066 \$ / \mathrm{MHz} /$ pop for regional and national lots respectively while sealed bid auctions increase normalized returns in national lots by $0.069 \$ / \mathrm{MHz} /$ pop. The rules about packaged bids and switching after the bidding process (columns 5 and 6) are also important. The flexibility to avoid lock-ins in a specific lot results in $0.067 \$ / \mathrm{MHz} /$ pop and $0.053 \$ / \mathrm{MHz} /$ pop in regional and national auctions while the packaged bids yield $0.031 \$ / \mathrm{MHz} /$ pop in regional auctions.

To further understand the link between auction formats and outcomes we break down the auction formats in the three previous categories (SMRA, clock and sealed bid) into 8 award classes while controlling for pricing rules as well as packaged bids and switching. These are shown in Table 2 for all licenses and national licenses separately (columns 1 and 2).

Overall the results across regional and national lots seem to be aligned in spite of the differences that characterize regional and national lots for operators and their bidding strategies. We find that in the regional lots case (column 1, Table 2) the SMRA design with augmented switching results in the highest normalized returns with 0.549 $\$ / \mathrm{MHz} /$ pop followed by CCA with core pricing with $0.206 \$ / \mathrm{MHz} /$ pop. In this case the option for switching is an important signal to participants. Given that a lock in can be avoided they seem to value this option and continue with their true valuation of the lots until the bidding is completed. Standard clock auctions report slightly lower results compared to CCA and they both represent improvements over the standard SMRA design that yields $0.133 \$ / \mathrm{MHz} /$ pop. Much lower in the list we find the sealed bid auctions and First Come First Served ones which are both significant improvements over Beauty contests with or without financial bid criteria.

In the national lots case (column 2, Table 2) we find that three auction designs are very close to each other, namely the CCA with core pricing, the SMRA with augmented switching and the Standard clock auctions. Among them the CCA with core pricing results in the highest returns with 0.339 \$/MHz/pop while the other two types have more than $10 \%$ lower normalized outcomes. The standard SMRA design is also high in the list with $0.203 \$ / \mathrm{MHz} /$ pop but clearly far from uncovering the true valuations compared to more recent designs.

Overall the SMRA with augmented switching and the CCA with core pricing appear to be highly improved designs in terms of the returns they can yield for governments. Understanding the valuations of participants and encouraging truthful bidding is a prerequisite for a good design. However other structural and competitive parameters may interfere in this relationship. Since we are mainly looking at the prices paid we can not directly assess whether these higher returns result in a more competitive market. In Sect. 5 we discuss these aspects of market entry, concentration and bidding behaviour. 


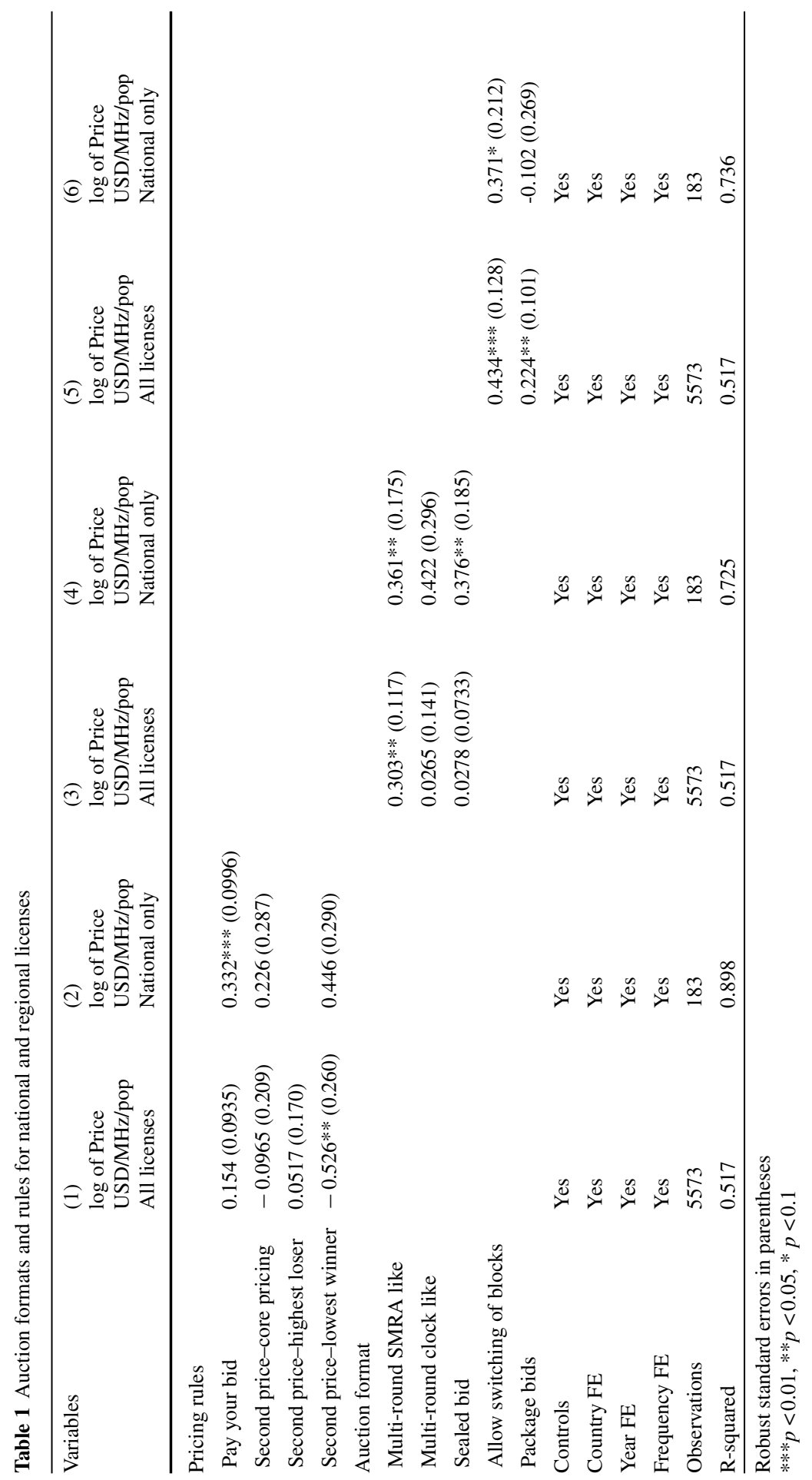


Table 2 Award class descriptions and rules linked to final prices for national and regional licenses

\begin{tabular}{lll}
\hline Variables & $\begin{array}{l}(1) \\
\text { log of price USD/MHz/pop } \\
\text { All licenses }\end{array}$ & $\begin{array}{l}\text { (2) } \\
\text { log of price USD/MHz/pop } \\
\text { National only }\end{array}$ \\
\hline $\begin{array}{l}\text { Award class description } \\
\text { CCA with core pricing }\end{array}$ & $\begin{array}{l}0.978^{* * *}(0.327) \\
\text { SMRA }\end{array}$ & $1.177^{*}(0.599)$ \\
SMRA with augmented switching & $0.728^{* * *}(0.137)$ & $0.851^{* *}(0.328)$ \\
Standard clock & $1.691^{* * *}(0.275)$ & $1.038^{* *}(0.454)$ \\
Sealed bid & $0.873^{* * *}(0.212)$ & $1.057^{* * *}(0.377)$ \\
Beauty contest with financial bid & $0.317^{* * *}(0.115)$ & $0.511(0.315)$ \\
$\quad$ criterion & $0.0841(0.113)$ & $0.0564(0.303)$ \\
First Come First Serve & & \\
Beauty contest without financial bid & $0.355^{* * *}(0.129)$ & $-0.247(0.398)$ \\
$\quad$ criterion & $0.0975(0.136)$ & $0.0380(0.399)$ \\
Controls (with pricing rules and & & Yes \\
switching) & Yes & Yes \\
Country FE & & Yes \\
Year FE & Yes & Yes \\
Frequency FE & Yes & 183 \\
Observations & Yes & 0.917 \\
R-squared & 5573 &
\end{tabular}

Robust standard errors in parentheses

$* * * p<0.01, * * p<0.05, * p<0.1$

\section{Spectrum prices and ownership}

A firm's bidding behavior in a given spectrum award may be influenced both by history, including its own legacy spectrum holdings, and by its expectations of the future concerning either the development of the market place in which it operates or the expected future pattern of spectrum awards or both. This section is concerned with the impact on bidding of a firm's current holdings, defined by the bands in which the licenses are located, the unexpired period of the relevant licenses and their expectations of the renewal procedure.

In the proposed framework, firms are often assumed to have two types of motive:

- Cost minimization or efficiency: this sees the firm's demand for its overall access to spectrum as derived from its expectation of its customers' demand for services. The demand for the spectrum in any awards thus depends on its expectation of the overall growth of the relevant downstream markets, its expected share of those markets, its existing endowments of spectrum, the auction price, and other factors such as its access to capital to acquire licenses.

- In the case of dominant firms, a foreclosure motive. This is the phrase used by the US Department of Justice (2014) to describe a particular form of strategic behavior in spectrum markets - the desire of predominantly large firms to push up the prices 
which its rivals pay for spectrum. A firm may pursue this strategy of raising its rivals' costs even if its own costs rise.

The former 'efficiency' motive will make firms' relative willingness to pay for spectrum in an auction depend on where they currently stand in relation to what they perceive to be the efficient combination of inputs into the production process (including in particular, the efficient combination of spectrum holdings and base stations) over the expected lifetime of the award (taking into account expectations of future awards).

A very crude index of operators' relative shortage of spectrum at the moment of an award is to compare their ratios of spectrum holdings to traffic carried, or-even more crudely-number of subscribers. This metric has a number of obvious difficulties, including the problem of aggregating spectrum holdings in different bands. But it also leaves out expectations. For example, if it is expected the market concentration will increase, then larger operators may expect a greater shortfall than smaller ones (other things equal) and this might 'explain' a positive correlation between willingness to pay in an auction and existing spectrum holdings.

In these circumstances we do not seek to investigate the motives underlying bidding behavior but to investigate whether there is evidence that the size of a firm's legacy holdings influences its auction bids. Building on Eqs. (3)-(6) we present our findings in Tables 3 and 4. Table 3 shows our first finding, that entrants systematically pay more if set-asides are not in place using normalized prices, i.e., for the same amount of spectrum compared to established players. The effect is relatively high at $0.079 \$ / \mathrm{MHz} /$ pop for all frequencies in regional lots and rises to $0.310 \$ / \mathrm{MHz} / \mathrm{pop}$ for national and commercial lots. This effect is surprising given that there is vast heterogeneity in prices paid within auctions. In fact, the effect appears to be as high as the differences across auction designs - namely the CCA with core pricing in national auctions versus the other designs. Looking at frequency related valuations we observe that the prices for commercial lots in national auctions are $0.034 \$ / \mathrm{MHz} /$ pop higher compared to other bands. In the other cases statistical significance is low to provide some further insights.

In Table 4 we introduce the historic ownership of spectrum into the regression framework. In this case we depart from the average prices per frequency band used in previous tables as the effects we are interested to capture relate to each operator separately (and the lots they acquired). Therefore, this analysis is performed at the lot level for regional and national auctions. To illustrate the effect, calculations based on Table 4 show that an operator that was awarded $30 \%$ of the spectrum auctioned in a previous competition is expected to pay $0.008 \$ / \mathrm{MHz} /$ pop in the next auction. Looking into the full history of auctions - that may include non commercial licenses and other types of spectrum - we find that the effect remains strong but drops substantially. We further seek to understand whether this relationship is linear and for this we add a quadratic term for the spectrum ownership variable. The results for the quadratic term suggest that there is a maximum of spectrum ownership beyond which operators stop imposing further increases of the nominal prices paid (inverted u-curve). This helps explain why in established markets entrants (with zero spectrum holdings as shown in Table 3) and smaller players (less than $35 \%$ of spectrum) appear to pay more. 
Table 3 Entry, sub $1 \mathrm{GHz}$ and award class descriptions linked to final prices for national and regional licenses

\begin{tabular}{|c|c|c|c|c|}
\hline Variables & $\begin{array}{l}\text { All frequencies } \\
\text { log of price } \\
\text { USD/MHz/pop } \\
\text { All licenses }\end{array}$ & $\begin{array}{l}\log \text { of price } \\
\text { USD/MHz/pop } \\
\text { National only }\end{array}$ & $\begin{array}{l}\text { (3) } \\
\text { Commercial } \\
\text { frequencies } \\
(2 \mathrm{G} / 3 \mathrm{G} / 4 \mathrm{G}) \\
\text { log of price } \\
\text { USD/MHz/pop } \\
\text { All licenses }\end{array}$ & $\begin{array}{l}\text { (4) } \\
\text { Commercial } \\
\text { frequencies } \\
\text { (2G/3G/4G) } \\
\text { log of price } \\
\text { USD/MHz/pop } \\
\text { National only }\end{array}$ \\
\hline $\begin{array}{l}\text { Entrant (no previous } \\
\text { ownership of spectrum) }\end{array}$ & $0.491 *(0.258)$ & $0.896 *(0.470)$ & $0.596 * *(0.298)$ & $1.116^{* * *}(0.334)$ \\
\hline $\begin{array}{l}\text { Auctions for } \\
\text { spectrum }<1 \mathrm{GHz}\end{array}$ & $0.192(0.333)$ & $0.302(0.306)$ & $0.156(0.341)$ & $0.203 *(0.116)$ \\
\hline $\begin{array}{l}\text { Controls (including auction } \\
\text { design, package bids, } \\
\text { switching) }\end{array}$ & Yes & Yes & Yes & Yes \\
\hline Country FE & Yes & Yes & Yes & Yes \\
\hline Year FE & Yes & Yes & Yes & Yes \\
\hline Frequency FE & Yes & Yes & Yes & Yes \\
\hline Observations & 5.573 & 183 & 3.082 & 135 \\
\hline R-squared & 0.522 & 0.925 & 0.524 & 0.942 \\
\hline
\end{tabular}

Robust standard errors in parentheses

$* * * p<0.01, * * p<0.05, * p<0.1$

This happens up until a player becomes 'established' and reaches the $35 \%$ spectrum ownership. From that point on operators tend to pay less in normalized terms. Testing with higher level polynomials confirms this observation.

In order to further analyze the relationship between spectrum ownership (in the previous round) and bidding behavior, we split the countries in two groups: the first one does not have any market-power related regulations on significant market power (SMP, source: ITU ICT eye); the second has explicit market-power regulations. We re-ran the models in Table 4 and plot the resulting u-shaped curves in Fig. 2. The results suggest that in cases where market power restrictions exist-or specific caps are in place - operators restrict (voluntarily or not) their acquisition of lots, possibly to a level that prevents any sanctions. The situation is different in countries or regions without such restrictions. One possible interpretation of this is that in the absence of SMP restrictions on operators, the likelihood of foreclosure is increasing in the percent of spectrum ownership of each operator.

\section{Conclusion}

In this paper we analyse the impact of auction design on final prices paid using a broad dataset of thousands of lots awarded over the period 1994-2015. We identify the key designs that result in the highest returns (SMRA with augmented switching and CCA with core pricing). We further look into the importance of structural market dynamics using the percent of spectrum awarded to each operator in the previous 


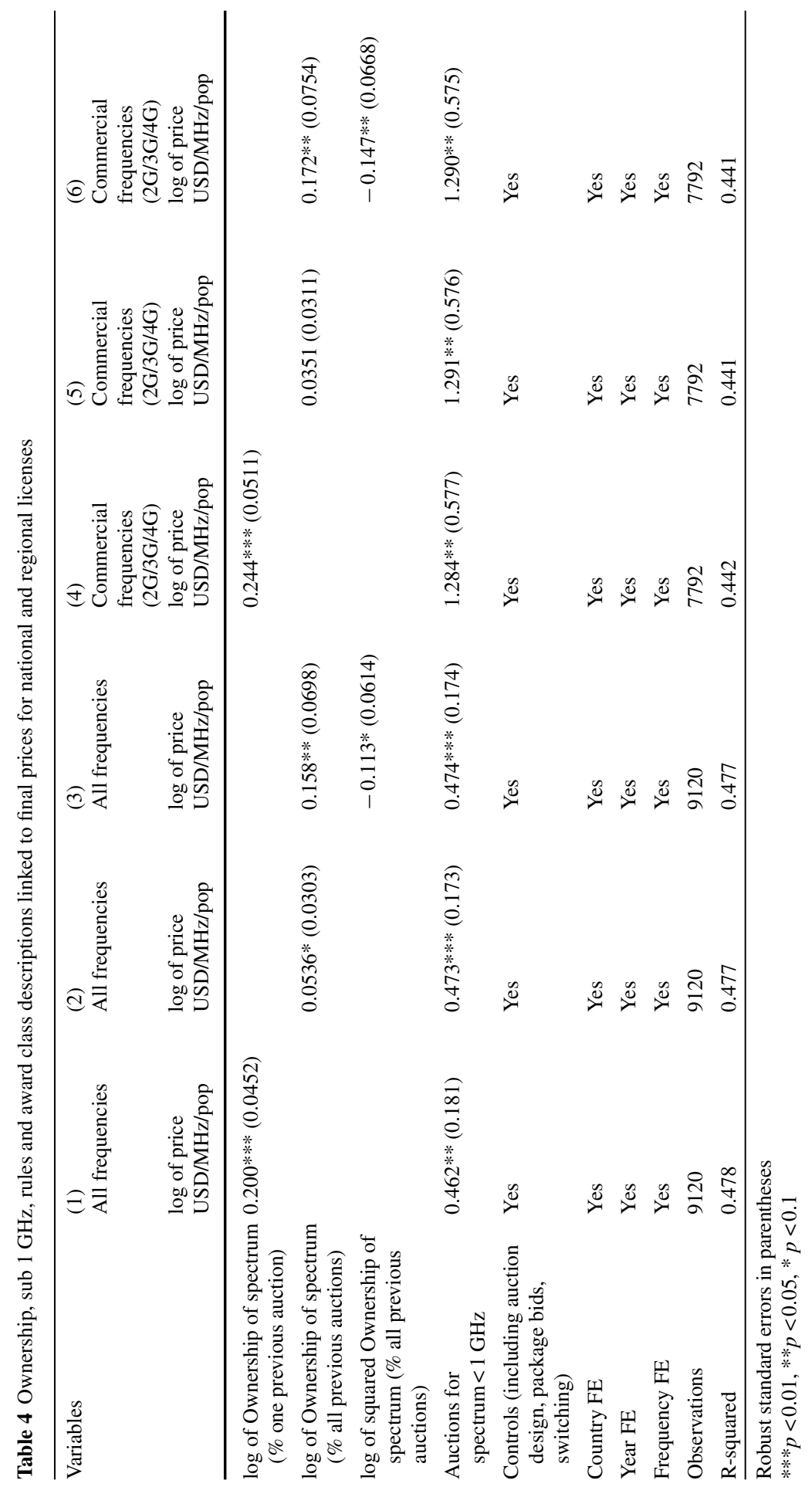




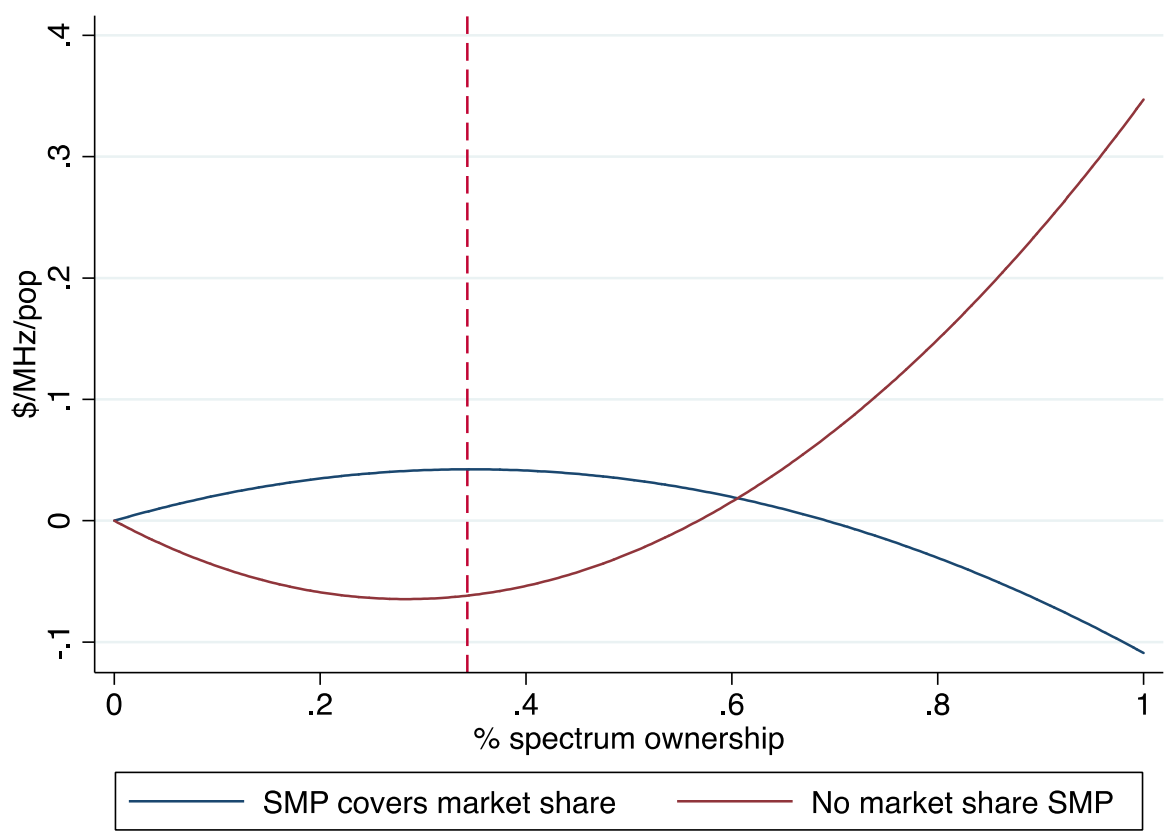

Fig. 2 SMP regulations and bidding behavior. The dashed line is the local maximum for cases where SMP covers market shares

round(s). We find a link between ownership and price paid. A past history of success in spectrum awards has a positive effect on prices paid subsequently up to a certain level and conditional on local rules around market concentration. It is possible that the manner in which this effect operates may depend upon local regulations, as our analysis indicates.

This study is a first step in the empirical analysis of auction outcomes at a global scale. We believe that future research based on more granular auction data can shed light not only on auction processes but also on the link between final prices paid in auctions and subsequent market outcomes, such as competitive structures, average revenues per capita, coverage, and new technology adoption levels.

Open Access This article is distributed under the terms of the Creative Commons Attribution 4.0 International License (http://creativecommons.org/licenses/by/4.0/), which permits unrestricted use, distribution, and reproduction in any medium, provided you give appropriate credit to the original author(s) and the source, provide a link to the Creative Commons license, and indicate if changes were made.

\section{Appendix}

See Tables 5, 6 and Figs. 3, 4 and 5. 
Table 5 Description of the variables in our sample

\begin{tabular}{|c|c|}
\hline Field & Description \\
\hline Award id & Unique identifier for each award \\
\hline Award name & Name of the award \\
\hline Country & Country the award was held in \\
\hline Format & Award format, e.g. SMRA, CCA, beauty contest \\
\hline Date & The end date of the award \\
\hline Number of bidders & The number of participating bidders in the auction. \\
\hline Number of MNOs & $\begin{array}{l}\text { The number of active MNOs in the country at the time of } \\
\text { the award (not including MVNOs) }\end{array}$ \\
\hline Available spectrum (MHz) & $\begin{array}{l}\text { The total amount of spectrum available in the award (should } \\
\text { be paired plus unpaired) }\end{array}$ \\
\hline Available spectrum (paired, MHz) & The amount of paired spectrum available in the award \\
\hline Available spectrum (unpaired, $\mathrm{MHz}$ ) & $\begin{array}{l}\text { The total amount of unpaired spectrum available in the } \\
\text { award }\end{array}$ \\
\hline Lotid & $\begin{array}{l}\text { Unique identifier for each lots (or, in the case where } \\
\text { lot-by-lot data could not be recorded, each winner's } \\
\text { winning package) }\end{array}$ \\
\hline Licence duration & $\begin{array}{l}\text { The term of the licence in years. This can be expressed as a } \\
\text { decimal to reflect non-whole years. }\end{array}$ \\
\hline Winner & The name of the winner of the licence. \\
\hline Frequency band & $\begin{array}{l}\text { Frequency band corresponding to the licence, e.g., } 800,900 \text {, } \\
1800,2100 \mathrm{MHz} \text {, and } 2.6 \mathrm{GHz} \text { etc. }\end{array}$ \\
\hline Region & The region corresponding to the licence \\
\hline Population covered & The estimated population covered by the licence \\
\hline Size $(\mathrm{MHz})$ & $\begin{array}{l}\text { Total amount of spectrum in } \mathrm{MHz} \text { of the licence (paired } \\
\text { plus unpaired spectrum) }\end{array}$ \\
\hline Paired (MHz) & Total amount of paired spectrum in $\mathrm{MHz}$ of the licence \\
\hline Unpaired (MHz) & Total amount of unpaired spectrum in $\mathrm{MHz}$ of the licence \\
\hline Lot price & $\begin{array}{l}\text { Licence price for the lot awarded. This is the 'headline' } \\
\text { price in local currency and does not include any annual } \\
\text { fees over the term of the licence plus any other fees e.g., } \\
\text { administrative fees }\end{array}$ \\
\hline Package price & $\begin{array}{l}\text { Licence price for a package, where it is not possible to split } \\
\text { this by lot (e.g. combinatorial auction). This is the } \\
\text { 'headline' price in local currency and does not include } \\
\text { any annual fees over the term of the licence plus any other } \\
\text { fees e.g., administrative fees }\end{array}$ \\
\hline Lot reserve price & $\begin{array}{l}\text { The reserve price for the lot awarded. This is in local } \\
\text { currency and does not include any annual fees over the } \\
\text { term of the licence plus any other fees e.g., administrative } \\
\text { fees }\end{array}$ \\
\hline Package reserve price & $\begin{array}{l}\text { The reserve price for a package (where applicable). This is } \\
\text { in local currency and does not include any annual fees } \\
\text { over the term of the licence plus any other fees e.g., } \\
\text { administrative fees }\end{array}$ \\
\hline
\end{tabular}


Table 5 continued

\section{Field}

Payment year

Amount due

Annualfee

Country area (Sq Km)

Continent

MajorGeoRegion

Currency

PPP rate (local currency to USD)

popDensity

urbanPop

GDPLocalCurrencyReal

GDPLocalCurrencyNominal

GNILocalCurrencyReal

GNILocalCurrencyNominal
Description

The payment year to which the amounts in the following two columns refer two. Year 0 represents upfront payments.

The total estimated payment amount that is due in this payment year for the corresponding lot/package

The component of the 'amount due' that reflects annual fees, as opposed to the licence fee established in the award process

The land area of the country in sq km

North America (NA), South America (SA), Oceania (O), Asia (A), Africa (AF) or Europe (E)

Eastern Africa, Middle Africa, Northern Africa, Southern Africa, Western Africa, Caribbean, Central America, South America, Northern America, Central Asia, Eastern Asia, SouthernAsia, South-East Asia, Western Asia, Eastern Europe, Northern Europe, Southern Europe, Western Europe, Australia and New Zealand, Melanesia, Micronesia, Polynesia

The local currency at the time of the award

Purchasing power parity (PPP) conversion factor is the number of units of a country's currency required to buy the same amount of goods and services in the domestic market that a U.S. dollar would buy in the United States. The reported rate is based on GDP and corresponds to the year of the award

Population density in specified year

Population living in urban areas as defined by national statistical offices. It is calculated using World Bank population estimates and urban ratios from the United Nations World Urbanization Prospects

GDP at purchaser's prices is the sum of gross value added by all resident producers in the economy plus any product taxes and minus any subsidies not included in the value of the products. It is calculated without making deductions for depreciation of fabricated assets or for depletion and degradation of natural resources

The nominal term is based on current prices in local currency, i.e., not inflation adjusted

The real term has been adjusted for inflation using the GDP deflator which is based in different years for different countries

GNI (formerly GNP) is the sum of value added by all resident producers plus any product taxes (less subsidies) not included in the valuation of output plus net receipts of primary income (compensation of employees and property income) from abroad. This data is in local currency, real versus nominal as per GDP terms above 
Table 5 continued

\begin{tabular}{|c|c|}
\hline Field & Description \\
\hline gini & $\begin{array}{l}\text { Gini index measures the extent to which the distribution of } \\
\text { income or consumption expenditure among individuals or } \\
\text { households within an economy deviates from a perfectly } \\
\text { equal distribution. A Lorenz curve plots the cumulative } \\
\text { percentages of total income received against the } \\
\text { cumulative number of recipients, starting with the poorest } \\
\text { individual or household. The Gini index measures the area } \\
\text { between the Lorenz curve and a hypothetical line of } \\
\text { absolute equality, expressed as a percentage of the } \\
\text { maximum area under the line. Thus a Gini index of } 0 \\
\text { represents perfect equality, while an index of } 100 \text { implies } \\
\text { perfect inequality }\end{array}$ \\
\hline inflationConsumerPricesPercent & $\begin{array}{l}\text { Inflation as measured by the consumer price index reflects } \\
\text { the annual percentage change in the cost to the average } \\
\text { consumer of acquiring a basket of goods and services that } \\
\text { may be fixed or changed at specified intervals, such as } \\
\text { yearly. The Laspeyres formula is generally used }\end{array}$ \\
\hline inflationGDPDeflatorPercent & $\begin{array}{l}\text { Inflation as measured by the annual growth rate of the GDP } \\
\text { implicit deflator shows the rate of price change in the } \\
\text { economy as a whole. The GDP implicit deflator is the } \\
\text { ratio of GDP in current local currency to GDP in constant } \\
\text { local currency }\end{array}$ \\
\hline telephonemainlines & $\begin{array}{l}\text { Telephone lines are fixed telephone lines that connect a } \\
\text { subscriber's terminal equipment to the public switched } \\
\text { telephone network and that have a port on a telephone } \\
\text { exchange. Integrated services digital network channels } \\
\text { ands fixed wireless subscribers are included }\end{array}$ \\
\hline mobilesubscribers & The number of mobile subscribers \\
\hline fixedBroadbandSubscribers & $\begin{array}{l}\text { Fixed broadband Internet subscribers are the number of } \\
\text { broadband subscribers with a digital subscriber line, cable } \\
\text { modem, or other high-speed technology }\end{array}$ \\
\hline
\end{tabular}

Table 6 A2 Frequencies of lots included in our sample
Frequency bands

\begin{tabular}{llll}
\hline $10 \mathrm{GHz}$ & $3.4-3.5 \mathrm{GHz}$ & $1600 \mathrm{MHz}$ & $800 \mathrm{MHz}$ \\
$11 \mathrm{GHz}$ & $3.4-3.6 \mathrm{GHz}$ & $1700 \mathrm{MHz}$ & $850 \mathrm{MHz}$ \\
$2.1 \mathrm{GHz}$ & $3.4-3.8 \mathrm{GHz}$ & $1800 \mathrm{MHz}$ & $870 \mathrm{MHz}$ \\
$2.3 \mathrm{GHz}$ & $3.5 \mathrm{GHz}$ & $1900 \mathrm{MHz}$ & $900 \mathrm{MHz}$ \\
$2.5 \mathrm{GHz}$ & $3.6 \mathrm{GHz}$ & $400 \mathrm{MHz}$ & \\
$2.6 \mathrm{GHz}$ & $3.6-3.8 \mathrm{GHz}$ & $410 \mathrm{MHz}$ & \\
$23 \mathrm{GHz}$ & $31 \mathrm{GHz}$ & $420 \mathrm{MHz}$ & \\
$24 \mathrm{GHz}$ & $32 \mathrm{GHz}$ & $450 \mathrm{MHz}$ & \\
$26 \mathrm{GHz}$ & $38 \mathrm{GHz}$ & $450-470 \mathrm{MHz}$ & \\
$26-27 \mathrm{GHz}$ & $40 \mathrm{GHz}$ & $500 \mathrm{MHz}$ & \\
$28 \mathrm{GHz}$ & $1450 \mathrm{MHz}$ & $678-686 \mathrm{MHz}$ & \\
$3.4 \mathrm{GHz}$ & $1500 \mathrm{MHz}$ & $700 \mathrm{MHz}$ & \\
\hline
\end{tabular}




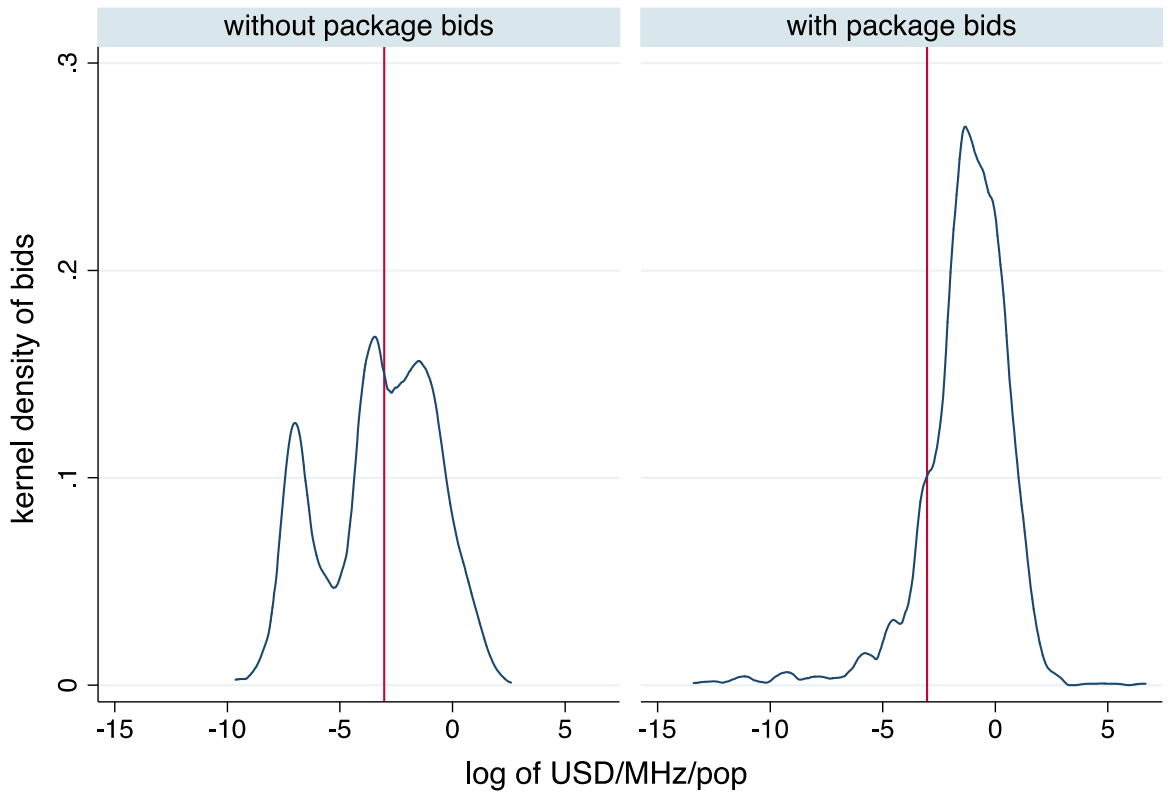

Fig. 3 Normalized returns ( $\$ / \mathrm{MHz} / \mathrm{pop})$ and use of packaged bids

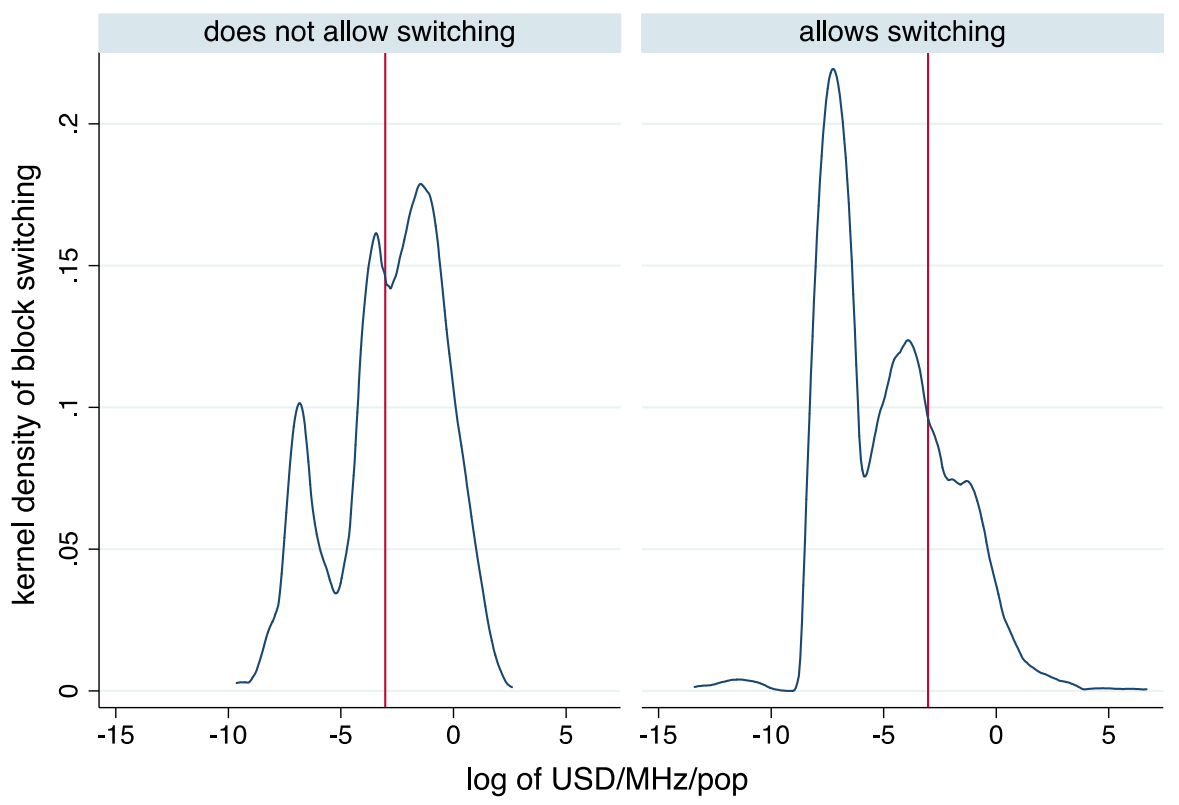

Fig. 4 Normalized returns (\$/MHz/pop) and spectrum block switching 


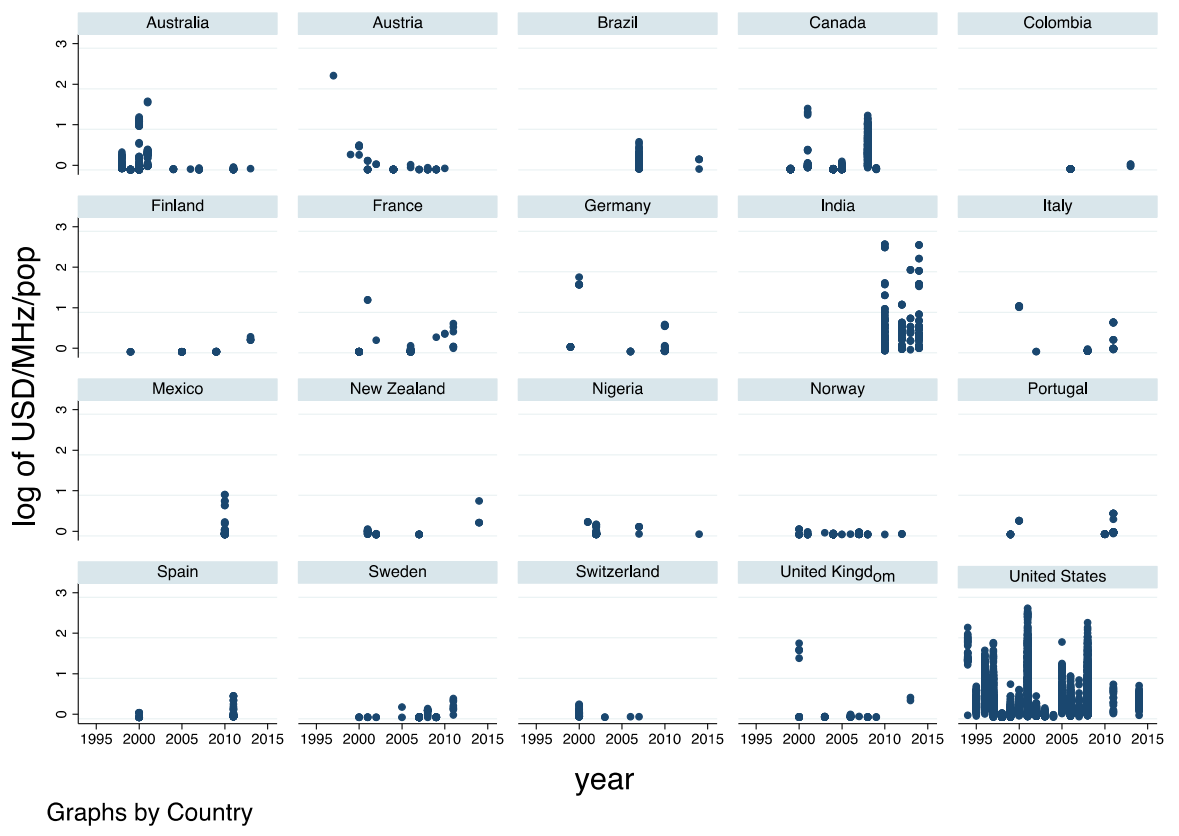

Fig. 5 Prices per lot by country and year (Note only countries with more than 50 observations or more are reported)

\section{References}

Ausubel, L. M., \& Cramton, P. (1998). Auctioning securities. University of Maryland Working Paper.

Bajari, P., \& Yeo, J. (2009). Auction design and tacit collusion in FCC spectrum auctions. Information Economics and Policy, 21(2), 90-100.

Binmore, K., \& Klemperer, P. (2002). The biggest auction ever: The sale of the British $3 \mathrm{G}$ telecom licences. The Economic Journal, 112(478), 74-96.

Cambini, C., \& Garelli, N. (2017). Spectrum fees and market performance: A quantitative analysis. Telecommunications Policy. Available at http://www.sciencedirect.com/science/article/pii/S03085961173005 63.

Cave, M., \& Valletti, T. (2000). Are spectrum auctions ruining our grandchildren's future? Info, 2(4), $347-350$.

Che, Y.-K., \& Gale, I. (1998). Standard auctions with financially constrained bidders. The Review of Economic Studies, 65(1), 1-21.

Chen, B. R., \& Chiu, Y. S. (2011). Competitive bidding with a bid floor. International Journal of Economic Theory, 7(4), 351-371.

Cramton, P. (2013). Spectrum auction design. Review of Industrial Organization, 42(2), 161-190.

Cramton, P., \& Schwartz, J. A. (2002). Collusive bidding in the FCC spectrum auctions. Contributions in Economic Analysis \& Policy, 1(1), 1-18.

Engers, M., \& McManus, B. (2007). Charity auctions. International Economic Review, 48(3), 953-994.

Gavious, A., Benny, M., \& Sela, A. (2002). Bid costs and endogenous bid caps. RAND Journal of Economics, 33, 709-722.

Jehiel, P. (2011). Manipulative auction design. Theoretical Economics, 6(2), 185-217.

Klemperer, P. (1999). Auction theory: A guide to the literature. Journal of Economic Surveys, 13(3), 227-286.

Klemperer, P. (2002a). What really matters in auction design. The Journal of Economic Perspectives, 16(1), 169-189. 
Klemperer, P. (2002b). Some observations on the British and German $3 G$ telecom auctions.

Klemperer, P., \& Pagnozzi, M. (2002). Advantaged bidders and spectrum prices: An empirical analysis. Working paper, Nuffield college, Oxford University.

Levin, J., \& Skrzypacz, A. (2016). Properties of the combinatorial clock auction. American Economic Review, 106(9), 2528-2551.

Medudula, M. K., Sagar, M., \& Gandhi, R. P. (2016). Telecom management in emerging economies. New Delhi: Springer.

Morey, M. (2001). Ensuring sufficient generation capacity during the transition to competitive electricity markets. Edison Electric Institute: www.eei.org.

Nyborg, K. G., \& Sundaresan, S. (1996). Discriminatory versus uniform Treasury auctions: Evidence from when-issued transactions. Journal of Financial Economics, 42(1), 63-104.

Reinhart, V., \& Belzer, G. (1996). Some evidence on bid shading and the use of information in the US treasury's auction experiment. Board of Governors of the Federal Reserve System.

Roider, A., \& Schmitz, P. W. (2012). Auctions with anticipated emotions: Overbidding, underbidding, and optimal reserve prices. The Scandinavian Journal of Economics, 114(3), 808-830.

Rosenkranz, S., \& Schmitz, P. W. (2007). Reserve prices in auctions as reference points. The Economic Journal, 117(520), 637-653.

Salant, D. J. (2014). Auction design, management, and strategy. Cambridge, MA: MIT Press.

van Bochove, C., Boerner, L., \& Quint, D. (2012). Anglo-Dutch premium auctions in eighteenth-century Amsterdam (No. 2012/3). School of Business \& Economics Discussion Paper: Economics. 